\title{
Measurements of Some Trace Elements in Street Dust in Zilfi Province at Saudi Arabia Using Inductively Coupled Plasma-Mass Spectrometer
}

\author{
Nawal M. Suleman*, Ibtihag A. Mohammad, Sultanah S. Almesned, Alanood A. Aljaghwani \\ Department of chemistry, Zilfi Faculty of Education, Majmmah University, Zilfi, 11932 P.O 1221, Saudi Arabia
}

\begin{abstract}
Dust has frequently been used as a material for monitoring trace elements polution. The wind may take the trace elements to the $\mathrm{f}$ arms. And we know that there are many farms around Zilfi Province., at Saudi Arabia . So in this study the concentrations of some trace elements $(\mathrm{As}, \mathrm{Cd}, \mathrm{Cr}, \mathrm{Pb}$, and, $\mathrm{Zn})$, in streets dust in major streets and inner ones in Hai Elsdeeg and Smnan at Zilfi Province have been studied for comparison, using Inductively Coupled Plasma-Mass Spectrometer (ICP-MS), after sieving and digestion using $\mathrm{HNO}_{3}, \mathrm{HCL}$ and $\mathrm{HF}$. Concentrations of most elements have been found less than allowed concentrations in literature, but the concentration of arsenic is found higher than the limit allo wed specially in some samples .. The concentrations of , $\mathrm{Cd},, \mathrm{Pb}, \mathrm{Cr}$, and $\mathrm{Zn}$, are high nearby car repair workshop and also at main streets especially in Hai Elsdeeg compared to Hai Smnan .
\end{abstract}

Keywords Street Dust, Trace Elements, Inductively Coupled Plasma

\section{Introduction}

Zilfi Province is Located on Riyadh, capital of Saudi Arabia approximately $260 \mathrm{~km}$ North . Dust has frequently been used as a material for monitoring trace elements pollution. In some instances dust may present significant pollution source when rain falls and washes the road surfaces and storms so causes increased metals input to rivers and sewage[1] .Young children have been identified as the group that is at highest risk. Also vegetables and fruits may be contaminated with superficial of dust[2]. The major source of trace elements for human is the food of plant and animal origin. Drinking water covers a few percent of the elements needed. Breathing and using dirty hands are other sources[3]. The damage that results from inhalation of elements is much more serve than that produced by swallowing. For these reasons; the study will measure the concentrations of some trace elements in streets dust in major streets and inner ones from Hai Elsdeeg and Smnan at Zilfi Province for comparison, using Inductively Coupled Plasma-Mass Spectrometer(ICP-MS). The wind may take the trace elements to the farms. And we know that there are many farms around Zilfi Province.

There are four main sources of trace elements in the street dust which are road traffic ,industrial activity,

* Corresponding author:

n.suleman@mu.edu.sa (Nawal M. Suleman)

Published online at http://journal.sapub.org/env

Copyright (C) 2012 Scientific \& Academic Publishing. All Rights Reserved weathered material and specific intermittent episode[4]. Elements identified as originating from auto mobiles are $\mathrm{Pb}$, $\mathrm{Cd}, \mathrm{Cu}, \mathrm{Zn}, \mathrm{Fe}, \mathrm{Cr}$ and $\mathrm{Ni}$. The morphology and chemical composition of heavy metal particles embedded in tire dust and traffic -related materials have been characterized [5].Simultaneous elemental analysis in dust of the city of Riyadh ,Saudi Arabia by (ICP-MS) [ 6], also this technique have been used in microwave digestion method of soil samples for toxic elements analysis[7]. The concentrations of 23 chemical elements have been determined using energy dispersive X-ray fluorescence (EDXRF)[8] . the elemental concentrations of heavy metal pollutants that may be present in street dust samples in Mubi, Adamawa state, Nigeria, were measured[9]. A few heavy metal contamination related studies in several cities from China over the past 10 years was reviewed[ 10]. The concentrations of $\mathrm{Fe}, \mathrm{Cu}, \mathrm{Cd}, \mathrm{Pb}, \mathrm{Zn}$ and $\mathrm{Ni}$ in the dusts were determined by atomic absorption spectrophotometer in Amman, Jordan[11], and in (Turkey)[12] . Soil samples from different roads in Jeddah city were collected and analyzed for their elemental composition[13] .

\section{Materials and Methods}

\subsection{Instrumentation}

The analytical determination of $\mathrm{As}, \mathrm{Cd}, \mathrm{Cr}, \mathrm{Pb}$, and , $\mathrm{Zn}$, was carried out by ICP-MS(Inductively Coupled Plas ma-M ass Spectrometer ):ELAN 9000 (Perkin Elmer Sciex Instrumento , Concord ,Ontario ,Canada).The Table(1) 
highlights the operating conditions of the instruments used in this study.

Table 1. Conditions of ELAN 9000 ICP-MS

\begin{tabular}{|c|c|}
\hline RF power & $1250 \mathrm{~W}$ \\
\hline Nebulizer gas flow & $0.92 \mathrm{~L} / \mathrm{min}$ \\
\hline Lens Voltage & $9.25 \mathrm{~V}$ \\
\hline Analog Stage Voltage & $-1762.5 \mathrm{~V}$ \\
\hline Pulse Stage Voltage & $1050 \mathrm{~V}$ \\
\hline Number of Replicates & 3 \\
\hline Reading / Replicates & 20 \\
\hline Scan Mode & Peak Hopping \\
\hline Dwell Time & $40 \mathrm{~ms}$ \\
\hline Integration & $1200 \mathrm{~ms}$ \\
\hline
\end{tabular}

\subsection{Reagents}

Nitric acid (69 \% v/v ) ,super purity grade from Romil, England . hydrochloric acid $(37 \% \mathrm{v} / \mathrm{v})$ and hydrofluoric acid $(40 \% \mathrm{v} / \mathrm{v})$ were suprapure from Merck Germany .High purity water obtained from Millipore Milli-Q water purification system was used throughout the work .

\subsection{Calibration}

The ICP-MS calibration was carried out by external calibration with the blank solution and three working standard solutions (20,40 and $60 \mathrm{ppm})$,starting from a $1000 \mathrm{mg} / \mathrm{l}$ single standard solutions for ICP-MS (A ristar grade , BDH laboratory supplies ,England for the elements: $\mathrm{As}, \mathrm{Cr}, \mathrm{Cd}, \mathrm{Pb}$, and $\mathrm{Zn}$.

\subsection{Sample Collection and Preparation}

The area of study (Hai Elsdeeg and Smnan in Zilfi Province ) was surveyed during October 2011 collecting (14 ) samples from different streets by gently sweeping along the edge of the road, then they were transferred to plastics bags ,and sieved through $200 \mathrm{~mm}$ thieve. Samples were prepared by accurately weighing a round $200 \mathrm{mg}$ of dust samples into a dry and clean Teflon digestion beaker ,6 $\mathrm{ml}$ of $\mathrm{HNO}_{3}, 2 \mathrm{ml} \mathrm{HCl}$ and $2 \mathrm{ml} \mathrm{HF}$ were added to the Teflon beaker .Samples were digested on the hot plate at $120-150^{\circ} \mathrm{C}$ for approximately 40 minutes .The resulting digest was not clear, so it was filtered through whatman filtered paper no.42.The filtered digest was transferred to a $50 \mathrm{ml}$ plastic volumetric flask and made up to mark using deionized water.A blank digest was carried out in the same way .

\section{Results and Discussion}

All calibration graphs are linear in the selected range of each element. The square of the correlation ( $\mathrm{r} 2$ ) ranges from 0.9985-0.099999 for most of the elements in this investigati on .Good precision values were obtained .The results have been reviewed in tables (2-7) and figures (1-6) .Street dust shows considerable metallic contamination deposits of vehicle-derived metals and to reduction of metal deposited on the road surface. The concentrations of individual trace elements in street dust correlate with traffic density. Distance from the roads, urban and suburban differences and the mode of traffic density.

Table 2. As concentration in Dust Samples $(\mu \mathrm{g} / \mathrm{g})$

\begin{tabular}{|c|c|c|}
\hline $\begin{array}{c}\text { Dust } \\
\text { sample } \\
\text { number }\end{array}$ & $\begin{array}{c}* \text { As Concentration Mean } \\
\pm * * \mathrm{SD}\end{array}$ & $* * * \% \mathrm{RSD}$ \\
\hline 1 & $28.12 \pm 1.12$ & 4 \\
\hline 2 & $22.12 \pm 1.83$ & 8.3 \\
\hline 3 & $56.62 \pm 0.47$ & 0.8 \\
\hline 4 & $4.75 \pm 0.09$ & 2 \\
\hline 5 & $9.3 \pm 0.1$ & 1.1 \\
\hline 6 & $12.53 \pm 0.08$ & 0.6 \\
\hline 7 & $13.81 \pm 0.33$ & 2.5 \\
\hline 8 & $11.99 \pm 0.18$ & 1.5 \\
\hline 9 & $10.86 \pm 0.11$ & 1.1 \\
\hline 10 & $41.14 \pm 0.22$ & 0.5 \\
\hline 11 & $9.38 \pm 0.1$ & 1 \\
\hline 12 & $12.39 \pm 0.15$ & 1.3 \\
\hline 13 & $17.18 \pm 0.19$ & 1.1 \\
\hline 14 & $12.95+0.17$ & 1.3 \\
\hline
\end{tabular}

Table 3. $\mathrm{Pb}$ concentration in Dust Samples $(\mu \mathrm{g} / \mathrm{g})$

\begin{tabular}{|c|c|c|}
\hline $\begin{array}{c}\text { Dust sample } \\
\text { number }\end{array}$ & $\begin{array}{c}* \text { Pb Concentration Mean } \pm \\
* * \mathrm{SD}\end{array}$ & $* * * \% \mathrm{RSD}$ \\
\hline 1 & $8.26 \pm 0.08$ & 1 \\
\hline 2 & $8.2 \pm 0.07$ & 0.9 \\
\hline 3 & $5.94 \underline{ \pm} 0.01$ & 0.2 \\
\hline 4 & $2.24 \underline{ \pm} 0.02$ & 1.1 \\
\hline 5 & $2.72 \underline{ \pm} 0.006$ & 0.2 \\
\hline 6 & $2.67 \pm 0.06$ & 2.4 \\
\hline 7 & $2.97 \pm 0.02$ & 0.7 \\
\hline 8 & $2.47 \pm 0.025$ & 1 \\
\hline 9 & $2.38 \pm 0.02$ & 0.8 \\
\hline 10 & $3.8 \pm 0.02$ & 0.4 \\
\hline 11 & $1.93 \pm 0.01$ & 0.5 \\
\hline 12 & $0.18 \pm 0.01$ & 0.8 \\
\hline 13 & $1.87 \pm 0.02$ & 0.9 \\
\hline 14 & $1.95 \pm 0.02$ & 1.1 \\
\hline
\end{tabular}

Table 4. Cd concentration in Dust Samples $(\mu \mathrm{g} / \mathrm{g})$

\begin{tabular}{|c|c|c|}
\hline $\begin{array}{c}\text { Dust sample } \\
\text { number }\end{array}$ & $\begin{array}{c}* \text { Cd Concentration Mean } \\
* * \mathrm{SD}\end{array}$ & $* * * \% \mathrm{RSD}$ \\
\hline 1 & $0.42 \pm 0.007$ & 1.8 \\
\hline 2 & $0.48 \pm 0.002$ & 0.7 \\
\hline 3 & $0.13 \pm 0.003$ & 2.2 \\
\hline 4 & $0.05 \pm 0.002$ & 4.2 \\
\hline 5 & $0.08 \pm 0.001$ & 0.8 \\
\hline 6 & $0.08 \pm 0.001$ & 0.9 \\
\hline 7 & $0.07 \pm 0.002$ & 3.5 \\
\hline 8 & $0.07 \pm 0.002$ & 2.5 \\
\hline 9 & $0.06 \pm 0.001$ & 1.4 \\
\hline 10 & $0.38 \pm 0.002$ & 0.5 \\
\hline 11 & $0.09 \pm 0.002$ & 1 \\
\hline 12 & $0.08 \pm 0.002$ & 1.7 \\
\hline 13 & $0.08 \pm 0.002$ & 2.5 \\
\hline 14 & $0.09 \pm 0.002$ & 1.3 \\
\hline
\end{tabular}


Table 5. Cr concentration in Dust Samples $(\mu \mathrm{g} / \mathrm{g})$

\begin{tabular}{|c|c|c|}
\hline $\begin{array}{c}\text { Dust } \\
\text { sample } \\
\text { number }\end{array}$ & $\begin{array}{c}* \text { Cr Concentration Mean } \\
* * \mathrm{SD}\end{array}$ & $* * * \% \mathrm{RSD}$ \\
\hline 1 & $6.43 \pm 0.04$ & 0.6 \\
\hline 2 & $6.41 \pm 0.08$ & 1.2 \\
\hline 3 & $6.91 \pm 0.02$ & 0.4 \\
\hline 4 & $3.63 \pm 0.05$ & 1.4 \\
\hline 5 & $5.63 \pm 0.05$ & 1.3 \\
\hline 6 & $6.4 \underline{ \pm} 0.07$ & 1 \\
\hline 7 & $6.31 \pm 0.1$ & 1.6 \\
\hline 8 & $5.64 \pm 0.04$ & 0.8 \\
\hline 9 & $4.98 \pm 0.05$ & 1 \\
\hline 10 & $8.11 \pm 0.04$ & 0.5 \\
\hline 11 & $4.01 \pm 0.1$ & 0.2 \\
\hline 12 & $4.2 \underline{ \pm} 0.04$ & 0.9 \\
\hline 13 & $5.6 \pm 0.01$ & 0.2 \\
\hline 14 & $4.23 \pm 0.04$ & 0.9 \\
\hline
\end{tabular}

Table 6. Zn concentration in Dust Samples $(\mu \mathrm{g} / \mathrm{g})$

\begin{tabular}{|c|c|c|}
\hline $\begin{array}{c}\text { Dust sample } \\
\text { number }\end{array}$ & $\begin{array}{c}* \text { Co Concentration Mean } \pm \\
* * \text { SD }\end{array}$ & $* * * \%$ RSD \\
\hline 1 & $71.37 \pm 0.36$ & 0.5 \\
\hline 2 & $52.93 \pm 0.5$ & 1 \\
\hline 3 & $15.58 \pm 0.09$ & 0.6 \\
\hline 4 & $14.47 \pm 0.17$ & 1.1 \\
\hline 5 & $17.55 \pm 0.13$ & 0.8 \\
\hline 6 & $13.36 \pm 0.15$ & 1.1 \\
\hline 7 & $15.21 \pm 0.1$ & 0.6 \\
\hline 8 & $11.79 \pm 0.14$ & 1.2 \\
\hline 9 & $17.1 \pm 0.24$ & 1.4 \\
\hline 10 & $10.47 \pm 0.02$ & 0.1 \\
\hline 11 & $13.71 \pm 0.1$ & 0.6 \\
\hline 12 & $19.83 \pm 0.1$ & 0.7 \\
\hline 13 & $61.1 \pm 0.42$ & 0.7 \\
\hline 14 & $25.99 \pm 0.17$ & 0.6 \\
\hline
\end{tabular}

*concentration Mean of 3 replicates, ${ }^{* *}$ standard Deviation, $* * *$ Percentage Relative Standard Deviation

Table 7. Comparison between the Maximum Concentrations Found in the Dust Samples and the Maximum Levels Ruled by Literature

\begin{tabular}{|c|c|c|}
\hline $\begin{array}{c}\text { Dust } \\
\text { sample } \\
\text { number }\end{array}$ & $\begin{array}{c}\text { Maximum Values } \\
\text { Found (mg/kg) }\end{array}$ & $\begin{array}{c}\text { Allowable } \\
\text { Values }(\mathrm{mg} / \mathrm{kg})\end{array}$ \\
\hline 1 & $\mathrm{~Pb}(8.26), \mathrm{Zn}(71.37)$ & $\mathrm{Pb}(100), \mathrm{Zn}(300)$ \\
\hline 2 & $\mathrm{Cd}(0.48)$ & $\mathrm{Cd}(5)$ \\
\hline 3 & $\mathrm{As}(56.62)$ & $\mathrm{As}(20)$ \\
\hline 10 & $\mathrm{Cr}(8.11)$ & $\mathrm{Cr}(100)$ \\
\hline \multicolumn{3}{|c}{} \\
\hline
\end{tabular}

As Concentration Mean

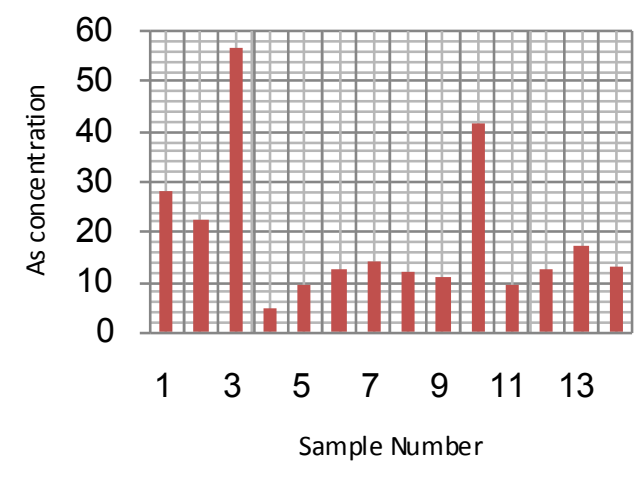

Figure 1. As Concentration In Dust Samples $(\mu \mathrm{g} / \mathrm{g})$

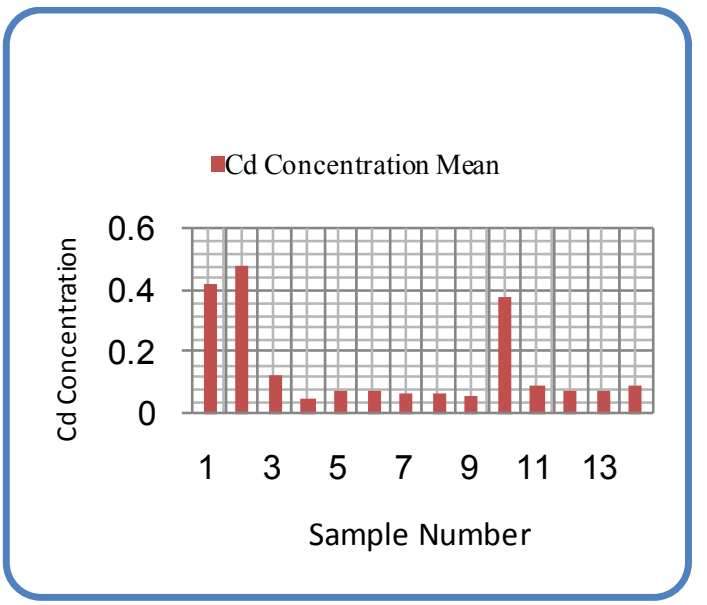

Figure 2. Cd Concentration In Dust Sample( $\mathrm{mg} / \mathrm{kg})$

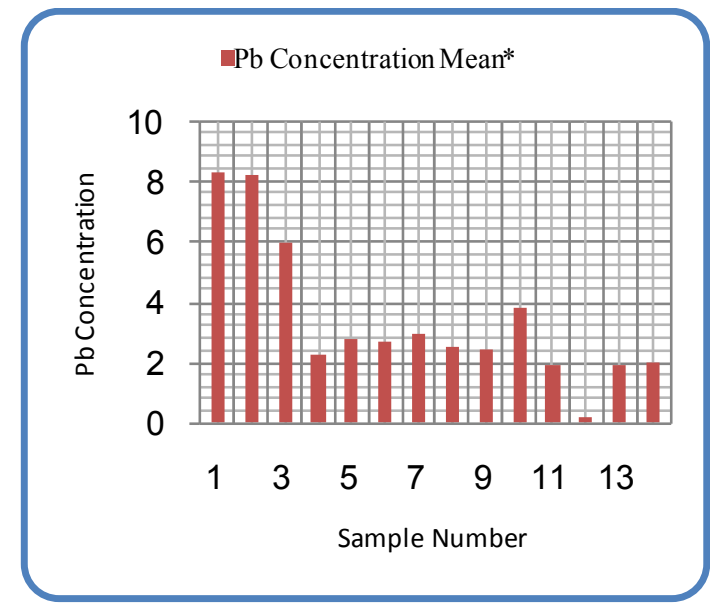

Figure 3. $\mathrm{Pb}$ Concentration In Dust Samples( $\mathrm{mg} / \mathrm{kg}$ ) 


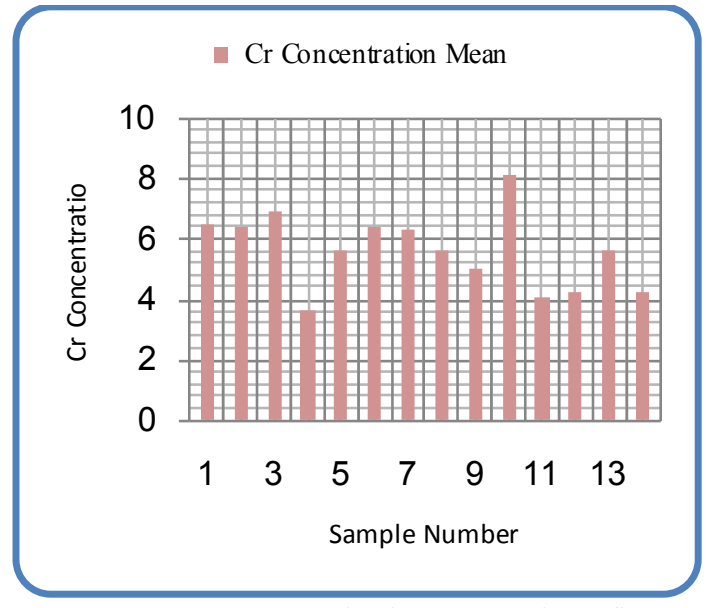

Figure 4. Cr concentration in Dust Sample $(\mathrm{mg} / \mathrm{kg})$

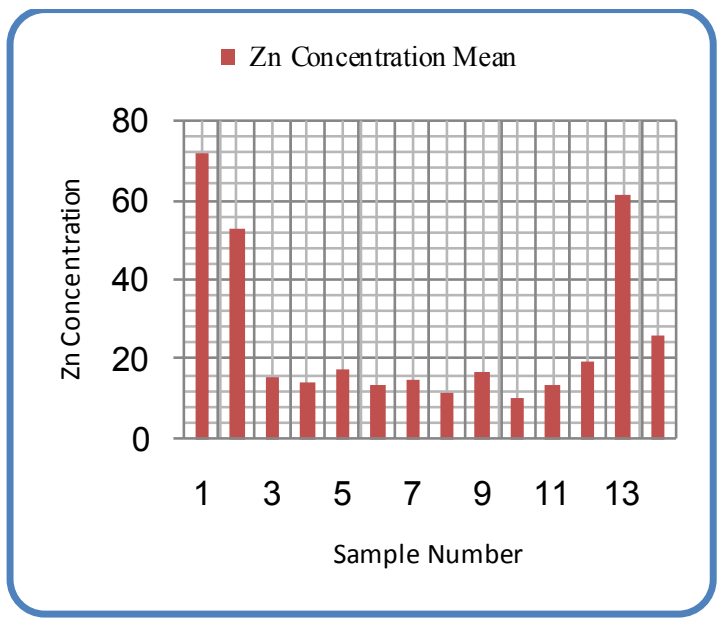

Figure 5. $\mathrm{Zn}$ concentration in Dust Sample( $\mathrm{mg} / \mathrm{kg})$

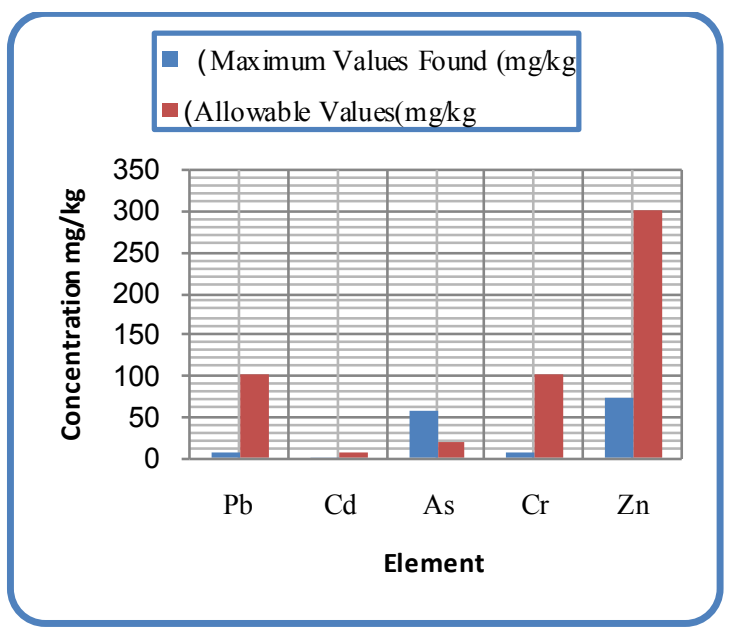

Figure 6. Comparison between the maximum concentrations found in the Dust Samples and the Maximum Levels Ruled by Literat ure

The concentrations of most elements have been found less than allowable concentrations in literature, but arsenic is found in concentrations higher than the limit allowed specially in the samples (1, 2, 3 and 10). These high levels of As may due to human activates(table (7)and fig.( 6) .

The high concentrations of $\mathrm{Zn}, \mathrm{Cd}, \mathrm{Pb}$, and $\mathrm{Cr}$ are found in the crossroads, nearby car repair workshop and also at the intersection of roads or area on main streets. Zn may have its origin from auto motive sources i.e. wear and tear of vulcanized rubber tires, lubricating oils and corrosion of galvanized vehicular parts. Study conducted in differing urban areas indicate that the most important source of anthropogenic $\mathrm{Pb}$ to street dust is from vehicular lead emissions. Throughout the literature, the source of $\mathrm{Cu}$ in the street dust was due to corrosion of metallic parts of cars derived from engine wear, thrust bearing, brushing, bearing metals and brake dust The $\mathrm{Cd}$ concentration in the street dust is likely to be associated to combustion product in the accumulators of motor vehicles or in carburetor $[5,7,9,11]$. Higher contamination was found in Hai Elsdeeg ( Table (7) as it contains the maximum values of , $\mathrm{Pb}, \mathrm{Cd}, \mathrm{Zn}$, and $\mathrm{As}$ compared to Hai Smnan . A further study can be made of the causes of increased concentration of arsenic allowable limits for large toxic for this element. These items can also be measured in the rest of the revival of the study of Zulfi parts .As the concentrations of trace elements are very important for plant growth, so an study can be done in the future to see some trace elements concentrations in the territory of some farms in Zilfy or other places in Saudi Arabia .

\section{Conclusions}

Concentrations of most elements have been found less than allowable concentrations in literature ,but arsenic is found in concentrations higher than the limit allowed specially in the samples $(1,2,3$ and 10).. The high concentrations of $\mathrm{Zn}, \mathrm{Cd}, \mathrm{Pb}$, and $\mathrm{Cr}$, are found in the crossroads, nearby car repair workshop and also at the intersection of roads or area on main streets which lies in Hai Elsdeeg, i.e. Hai Elsdeeg was found to be mo re contaminated compared to Hai Smnan

\section{ACKNOWLEDGEMENTS}

The authors gratefully thank Majmmah University for their financial support. Also express gratitude to Dr Kamal O.Ahmed at King Suad Univrsity for provid ing the support to complete this work.

\section{REFERENCES}

[1] Batterman S.A,Dzubay T.G. and Baumgardner R.E. Development of crustal profiles for rec eptor modeling,Atoms. Environ, 22,1821-28(1988).

[2] Shen,X.M.,et.al, Childhood Lead Poisoning in China ,Sci. Total Environ., 181 , (1996.)101-109.

[3] W.X. Liu, L.F. Shen, J.W. Liu, Y.W. Wang, S.R. Li, Uptake of toxic heavy metals by rice(Oryza sativa L.) cultivated in the agricultural soils near Zhengzhou City, People's Republic of China, Bulletin of Environmental Contamination and Toxicology 79(2007) 209-213. 
[4] Fergusson Jack E. and Kimnicholasd, the science of the Total Environment,(100)1991.

[5] A.Kouji and T.Yoshiaki,Environment International 30,1009-1017(2004).

[6] Ahmed K.O.,Al-Swaidan H.M. and Daviws B.E.,The Science of the Total Environment ,138\(1993),207-212

[7] Alotaibi,F.M.,Alghamdi,A.H.,and Alswaidan,H.M.,J.Saudi Chem.Soc.,Vol.10,No1;pp.1-8(2006) .

[8] Z.L.L. Yeunga, R.C.W. Kwokb, K.N. YuApplied Radiation and Isotopes 58 (2003) 339-346
[9] Shinggu, D. Y.1, Ogugbuaja, V. O.2, Barminas, J. T.1,3 and Toma, I.International Journal of Phy sical Sciences Vol. 2 (11), pp. 290-293.

[10] Binggan Wei a,b, Linsheng YangMicrochemical Journal 94 (2010) 99-107

[11] Omar Ali Al-Khashman, Environ Geochem Health (2007) 29:1-10.

[12] Şerife Tokalığlu Şenol Kartal Atmospheric Environment 40, (16) 2006, 2797-2805

[13] MohammadW. Kadi, Journal of Hazardous Materials 168 (2009) 1280-1283 